\title{
Agriculture 4.0: the theoretical concept and its practical implementation
}

\author{
Vyacheslav Polyakov ${ }^{1, *}$ \\ ${ }^{1}$ Don State Technical University, Gagarin sq., 1, Rostov-on-Don, 344003, Russia
}

\begin{abstract}
The paper discusses the main aspects of the formation and development of the "Agriculture 4.0"; its basic directions of the implementation are the active use of various digital technologies to be founded for the introduction of qualitatively new approaches to organizing the activities of the agricultural enterprises. Moreover, the formation of the digital platforms is considered as one of such approaches improving economic organizational and managerial relations that take place in the economic activity process of the agricultural enterprises. The conducted analysis made it possible to give the practical implementation of the ideas developed in the "Agriculture 4.0" concept. It is capable of both significantly improving efficiency of the agricultural production and reducing the dependence of the agro ecosystems` functioning from natural factors as well as contribution to the ecologization of the agricultural production processes.
\end{abstract}

\section{Introduction}

It is solved successfully the problems which are facing both individual agricultural enterprises and national agriculture in general and presupposed the potential use of the digitalization of the agricultural production, particularly in scientific and methodological terms according to the postulates of the "Agriculture 4.0" concept's implementation and the industry and corporate digital platforms ' development based on technological processes.

The mentioned concept assumes that the tasks of managing the interfarm (in terms of managing the value chain) activities of the agricultural enterprises should be solved on the basis of processing the heterogeneous data obtained using sensors, machines, drones and satellites and processed using modern information technologies. The obtained data processing results are used to analyze the past and predict the future for making more timely and accurate decisions through constant monitoring.

It should be noted that, an increasing number of the theorists and practitioners agree with agricultural digitalization which provides the engineering optimization of the agricultural production systems, value chains and food systems. In addition, it contributes to the solution of social and environmental problems, which determines the importance and relevance of the study of various aspects of the issues related to the formation of the "Agriculture 4.0" concept and the implementation of its provisions in practice

\footnotetext{
* Corresponding author: Polakoww@rambler.ru
} 


\section{Methods and Materials}

The global mainstreaming of the digital technologies consents many researchers who support the Fourth Industrial Revolution with its key characteristic which had been transited the business entities to the organizational activities based on the various use of the digital technologies.

According to researchers, the practical use of the Fourth Industrial Revolution was given by the project initiated in 2011 by the German government to promote deep production digitalization. [1]

The theoretical basis of the concept was proposed by the Chairman of the World Economic Forum K. Schwab. After given analysis of various formational aspects, the Industry 4.0 became the subject of urgent discussion among scientific and industrial partnerships. At the same time, the main attention is paid to the study of the following aspects of the practical implementation of the ideas developed in the concept:

- availability of business and government to use the potential of the Internet and the "Internet of things" in practice; [2]

- digitalization of business processes in enterprises;

- digital mapping and virtual modeling;

- smart manufacturing.

Under these circumstances, the Industry 4.0 model, which is the objectification of the revolution conceptual ideas, is based on an orientation towards eliminating the boundaries between the physical and virtual world. [3] The Industry 4.0 concept is a collective term for technology and value creation in the digital era.

Cloud computing, big data, open source technologies, the Internet of things and a host of other technologies form the practical implementation of the Industry 4.0 vision. Realizing the importance of their use, a number of states are implementing program initiatives in this area at the government level. Among them are, for example, Nouvelle France Industrielle in France, Made in China 2025 in China, the Coalition of Smart Manufacturing Leaders in the USA and so on.

It should be noted that, while the problem of forming foundations of the Industry 4.0 has been in the area of global research attention for almost a decade, its specific aspects related to the development, the Agriculture 4.0 began to be widely discussed only a few years ago. As a rule, this concept is understood as an agricultural production system based on the use of a combination of various digital technologies aimed at increasing yields and sustainability of crops, improving working conditions and the products quality. [4]

The use of these technologies consents the targeted intervention in development of the agricultural crops, significant savings in material, time consuming and carrying out more effective measures that have a positive effect on the quantitative and qualitative characteristics of the agricultural production process. In addition, many researchers focus on the significant potential of the "Agriculture 4.0" concept in achieving sustainable development goals. [5]

In this paper, the presented study was carried out on the basis of a theoretical analysis of the scientific literature; a descriptive method outlines the specific characteristics of the digital technologies` use in the agricultural sector as well as the comparison, analogy and systematization methods.

\section{Results}

The intensification of the agricultural production process has led to the emergence of serious environmental problems such as soil degradation, erosion processes and environmental pollution. [6] As a consequence, this leads to the loss of the soil quality and 
the further impossibility of providing the required amount of those ecosystem services that the soil was guaranteed to provide humanity until recently. [7]

There is notion that the large-scale use of the industrial methods in the agricultural management, is one of the consequences of the large-scale soil degradation, and it is postulated that "Agriculture 4.0" should imply the introduction of both technological and ecosystem innovations.

In this paper, it should be admitted that in the early definitions of the essence of ecoinnovations in relation to their use in agriculture, the emphasis was on the focus of this class of innovations on minimizing the negative impact on the environment in the processes of the agricultural production. However, with the complex nature of existing environmental problems, it became quite obvious that the most important direction of the eco-innovation activity is to focus on finding ways to reduce the consumption of the natural resources, which would give agro ecosystems to fully implement their function of providing ecosystem services. [8]

One of the application's implementations of such innovations is the development of the "Smart farming", which is an innovative economic and production system functioned on the basis of the formalized methods of organizing information streams. At the same time, the use of resource-saving digital technologies localized in the coordinates of each individual field enables to decrease dramatically the obtaining production cost as well as reduce significantly the anthropogenic impact degree on the environment.

It is mentioned the empirical studies illustrating the positive impact of the process which improves the agricultural land use systems in providing such types of the ecosystem services as the $\mathrm{CO} 2$ emission absorption and many other pollutants, improving the green planting systems, preserving biodiversity, developing recreational areas and others. [9]

The main directions of the "smart farming" development systems in modern conditions are as follows:

- ensuring the development of the digital systems for managing the agro-ecological situation in real time;

- software implementation of the intelligent decision-making support systems that increase the environmental and economic efficiency of the agricultural production;

- modernization of the digital models for using cloud technologies, big data processing systems, artificial intelligence technologies and neural network modeling;

- introduction of the universal mobile telecommunication facilities based on intelligent information systems and simulation technologies;

- development of the software systems for modeling the development of the agricultural crops with soil-climatic and agro biological conditions;

- application of the results of the remote sensing and satellite monitoring using multispectral cameras to improve methods for increasing the land productivity;

- use of the remote sensing data obtained using unmanned aerial vehicles to monitor the agro ecosystem online;

- development of the intelligent models contributing the different farming regimes on parameters of resource consumption and crop productivity.

To ensure optimal conditions for the agricultural crops 'development, it is necessary to have the most complete and accurate information about composition of the soil characteristics (the amount of nutrients in the soil, moisture, density and so on) in certain areas of the field. Therefore, one of the main directions of the practical application of the "Agriculture 4.0" concept is the management of the crop productivity, which makes it possible to give the space-time variability of the plant growing environment. In this regard, the most detailed use of the fertilizers, plant protection products, biologically active additives, water and energy resources ensures a more uniform development and maturation 
of the crops, minimizes the loss of the nutrients and, ultimately, leads to an increase in the quality and a decrease in the cost of the crop production.

The technological foundation for the approach implementation is the use of such systems, namely:

- high-precision positioning (GPS), which provide an accurate determination of the technical equipment location used in land cultivation;

- automated control systems, which simplify the implementation of different tasks related to the management of the agricultural machinery and are divided into the following types:

1) auxiliary steering systems which imply the need to participate in the control of the operator and to drive the vehicle along a given course with recommendations of the global positioning systems;

2) automated steering systems, which not only automate the process of the moving vehicles, but also provide a higher quality of the technological processes;

3 ) intelligent guidance systems containing in their arsenal various control patterns and used in conjunction with the two above-mentioned systems;

4) electronic systems that ensure the integration of the technical devices or their components with the control center;

5) systems for applying fertilizers with a differentiated rate, which uses the ability of the technical means to adapt the parameters of their work in accordance with the current requirements of the landscape, the characteristics of the plant development and so on.

- geographic information systems used to create field maps which display the soil type, the nutrients composition in it, acidity, moisture, weed infestation, disease and pest infestation;

- remote sensing sensors that provide non-contact data collection on the soil condition and crops.

The specified equipment is installed on tractors, combines, other vehicles as well as on aircraft. With satellite imagery and other modern information technologies, the real necessity of the soil fertilizers, plant protection products and other factors of the crop formation are determined for each separate area.

As evidenced by foreign and local experience, the digital technologies ' usage makes it possible to at least double the fertilization efficiency. The discrete fertilization reduces unproductive resource consumption and increases the productivity of the field parts with low soil fertility potential.

Besides, the most important element of the practical implementation process of the "Agriculture 4.0" concept is the "Internet of things" development that is a technology for integrating physical objects equipped with communication devices into a single network for the purpose of collecting, exchanging and analyzing information. In combination with various other elements of the IT infrastructure, the "Internet of things" bases on practical implementation of the smart farming concept. According to experts, in 201530 million the "Internet of things" devices and vehicles were used in the agricultural production system on a global scale, in the early 2020 s their number reached to 75 million units. [10]

The following technological solutions can be noted as typical examples of using the capabilities of the "Internet of things" in the digitalization process of the agricultural production:

- smart sensor Libelium, which monitors the development process of the most "demanding" vineyards, orchards, greenhouse crops, etc. and determines the required rate of the fertilization on its basis;

- Sentera sensors, which are a small camera with two sensors and are designed to determine the vegetation index of plants in harsh climatic conditions; 
- CropX soil condition sensors connected to the Internet and analyzing the soil condition in a specific area of the field and notifying the user about the need for irrigation via a mobile application;

- Semios sensor system, which gives you opportunity to control the pest populations in crops using RF-modules based on SNAP and gateways, which are located throughout the field and track the pests ' presence in a certain area; in this case, if their critical number is exceeded, a corresponding message is sent to the farmer;

- Bosch Field Monitoring system, a system based on constant temperature measurement, avoids crop losses due to frost and is used in the cultivation of crops such as grapes, citrus fruits, tomatoes and olives.

The technologies of the "Internet of things" are also actively used in the regulating use processes of the water resources. In particular, such major world manufacturers as Lindsay Corporation, Reinke Manufacturing, Valmont Industries increasingly associate their latest developments with a focus on the development of precision irrigation technologies which involve remote monitoring and wireless control of the sprinkler systems as part of the implementation of various technological approaches as traditional pre-irrigation based on variable irrigation rates (VRI) and differential fertilization with irrigation water. For example, Lindsay Corporation has developed such an innovative irrigation management tool as FieldNET, which is a remote control and management tool for irrigation systems. This tool can be installed on most smartphones and tablets and you can monitor and control what operations the sprinklers are performing at any stage of the agricultural cycle. In turn, Trimble has developed an automatic sprinkler on and off system to improve irrigation of the corners and overhangs in the field, which eliminates the problems associated with unproductive water use and waterlogging of the field area problem.

The use of modern information technologies and high-tech computer tools for the intellectual data analysis of the agricultural production processes offers the challenge in the formation of qualitatively new technological approaches to the cultivation of the agricultural crops for ensuring the economic and environmental efficiency of the agricultural production.

The use of the intelligent information systems can improve the quality of production processes, prevent land degradation and ensure efficient and rational use of natural resources. Solving the problem of preventing the degradation of the agricultural landscapes and ensuring their sustainability requires the use of the automated information technologies for monitoring fertility management. [11]

Particular attention is paid to the geoinformation systems using data from satellite monitoring and remote sensing of the Earth. This circumstance is due to the territorial dispersion of the managed objects, the possibility of building digital models with spatially distributed factors as well as the possibility of analyzing actual and model calculated data with their subsequent visualization on maps, which analyze situation and monitor the cultivated lands.

The use of the specialized GIS for the implementation of the smart farming technologies consents to consider each agricultural field as a heterogeneous land, dividing it into a conditional number of homogeneous parts (management units), each part forms its own reclamation regime and involves the use of the differentiated and strictly standardized fertilization rates with the set parameters of quality and volume of the obtained agricultural products.

Specifically, the use of the Vega-Science satellite service makes it possible to define the direction of change in soil properties in the context of determining the feasibility of the cultivating individual crops as well as tracking the land condition, monitoring the development and prevention of the degradation processes. 
Also, the practical implementation of the "Agriculture 4.0" concept predetermines the formation of qualitatively new integrated models for the agricultural production development, some of which are presented in Table 1.

Table 1. Characteristics of new integrated models of agricultural production development [12].

\begin{tabular}{|l|l|}
\hline \multicolumn{1}{|c|}{ Model } & \multicolumn{1}{c|}{ Characteristic } \\
\hline Smart farms & $\begin{array}{l}\text { Agricultural enterprises striving for maximum autonomy based on } \\
\text { digitalization of agricultural enterprises; its management is based on } \\
\text { the integrated use of sensor technologies, robotics, telematics and } \\
\text { artificial intelligence }\end{array}$ \\
\hline Closed farms & $\begin{array}{l}\text { Agricultural enterprises using alternative resources, including spatial } \\
\text { ones (desert crop production, marine farms, etc.) }\end{array}$ \\
\hline Urban farms & $\begin{array}{l}\text { Enterprises that provide the ability of producing agricultural products } \\
\text { (usually crop production and recirculating aquaculture) in limited } \\
\text { areas within an urban area }\end{array}$ \\
\hline
\end{tabular}

\section{Discussion}

The foreign researchers have contributed greatly to the formation and practical filling of the essential content of the "Agriculture 4.0" concept; we note that various aspects of this issue are being actively developed by local scientists.

In particular, the studies of well-known scientists A.F. Rogacheva and E.V. Melikhova are devoted to the problems of using unmanned aerial vehicles and artificial neural networks in agricultural production. As part of their research, they proposed approaches to the binary classification of the agricultural land condition based on the analysis of highresolution aerial photographs, programming the development of the agricultural production systems based on retrospective data on the yield of the agricultural crops as well as subsequent image analysis and vegetation indices`calculation. [13]

V.V. Borodychev considers the possibilities of the agricultural production management using modern GIS technologies for monitoring the operation of the technical means in real time, involving the formation of a specialized list of the interactive interaction segments as well as the use of multifunctional software systems for data analysis and intelligent decision support.

I.F. Yurchenko's scientific papers are devoted to the problems of information support for decision-making on the management of an agricultural complex in the context of the following aspects:

- possibility of using intelligent systems and technical cybernetics methods;

- automation and mathematical modeling of the technological control processes in agriculture;

- development, implementation and adaptation of information management systems in agro-industrial production;

- development of the automated intelligent control systems for agricultural production processes based on the cloud technologies, methods of processing big data, neural network modeling. [14]

It is considered the trends in the digitalization development of the agro-industrial sphere and the formation of the "Agriculture 4.0" concept necessitate the development of complex solutions that, on the one hand, integrate various digital tools aimed at solving a wide range of tasks facing agricultural enterprises, and, on the other hand, ensure effective interaction actors of various levels related to various aspects for solving these problems. These purposes can be achieved by formation the digital platforms of the agricultural production profile. 
Technologically, a digital platform is a collection of digital data and tools for their processing, integrated into a single automated system and placed in a concentrated form in a specific subject area of the information space, designed to provide a customer with the ability to remotely access digital services set on the platform. [15]

The essential content of the main attributes of the digital platform is illustrated in Table 2.

Table 2. Essential content of the main attributes of the digital platform.

\begin{tabular}{|l|l|}
\hline \multicolumn{1}{|c|}{ Attribute } & \multicolumn{1}{c|}{ Content } \\
\hline Appointment & Concentration of information and its distribution \\
\hline Object & Set of digital data, digital services \\
\hline Subjects & Many interested users \\
\hline Location & Information network space \\
\hline Possession & Platform Creator \\
\hline Access method & Remote \\
\hline Economic sense of use & Reducing costs due to the use of digital services \\
\hline
\end{tabular}

Currently, the Ministry of Agriculture of the Russian Federation is developing to form the National Platform "Digital Agriculture" as a single system integrated with digital subplatforms for managing agricultural production at various ranges (Fig. 1).

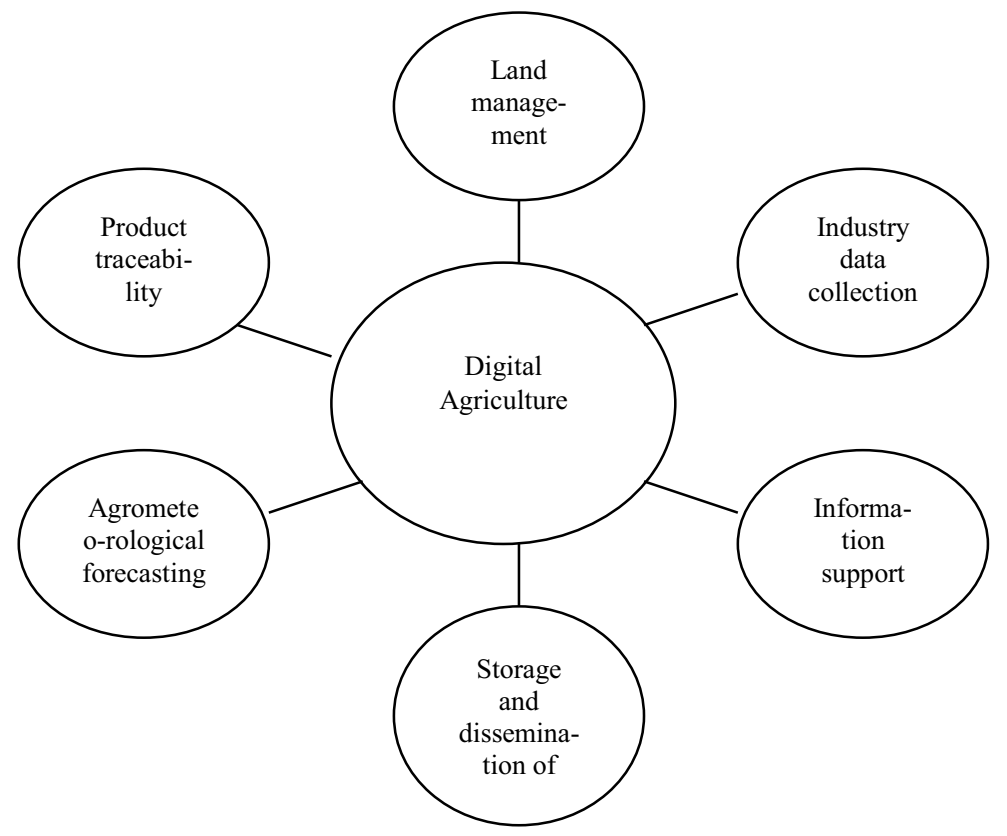

Fig. 1. Sub-platforms of National Platform "Digital Agriculture".

The main purpose of its formation is determined to support the digital transformation of local agriculture through introduction of the platform solutions to ensure a technological breakthrough in the agricultural sector and increase productivity of the digital agricultural enterprises.

In total, the platform will include more than 50 services required to ensure digital governance of the industry. The organization of interaction between platform participants in digital form will lay the found for implementation of qualitatively new approaches to agricultural production, focused on ensuring the reproduction of the natural resources. 
The greatest effect of the digital platforms introduction within the agro-industrial sector can be achieved through the implementation of a two-tier approach to ensuring their functioning.

At the first level, they should be corporate-level systems that integrate a variety of information on the activities of a particular economic entity including that obtained through the modern technological tools.

Additionally, this information concentrated in the data storage, being subjected to extensive analysis and processing, forms the basis for the development of the most adequate management decisions for current situation based on the electronic adoption support system.

Therefore, the second level of the digital platforms in the land reclamation sector is a space for information and business interaction of various economic entities and management structures that are directly related to the functioning and development of the agricultural production sector.

Whereby the access to certain information located at the first level of platforms and related to the activities of a particular farm can be limited for other participants by certain filters. Simultaneously, it becomes possible for farm specialists to integrate corporate information with open data of other subjects of the agricultural production and various management levels which significantly expands the possibilities of increasing the efficiency of their activities.

\section{Conclusion}

The current experience in the use of a wide range of opportunities provided by the practical implementation of the ideas developed in the "Agriculture 4.0" is capable of improving significantly the efficiency of the agricultural production and reducing the dependence of the functioning processes of the agro ecosystems on natural factors and contributing to greening processes of the agricultural production by reduction the level of resource intensity and the degree of negative impact on the natural environment.

The use of these opportunities seems to be the most effective in the implementation of an integrated approach, which involves the formation of two-level digital platforms with foundation for the implementation of qualitatively new approaches to solve a wide range of problems facing agricultural producers.

The agricultural enterprise in the digitalization process has the opportunity to form a model of its development using a number of strategic approaches, which are (Fig. 2):

1. The implementation of a resource advantage strategy focused on the use of standard competencies and standard resources.

2. The implementation of a strategy develops a resource approach and involves the use of digital resources, which are managed on the basis of standard competencies.

3. The implementation of the strategy realizes opportunities which involve the search for new directions of the organization's activities on its available resources based on the digital competencies.

4. The implementation of the strategy develops opportunities based on the development of new digital competencies in order to use new opportunities generated by digital resources. 


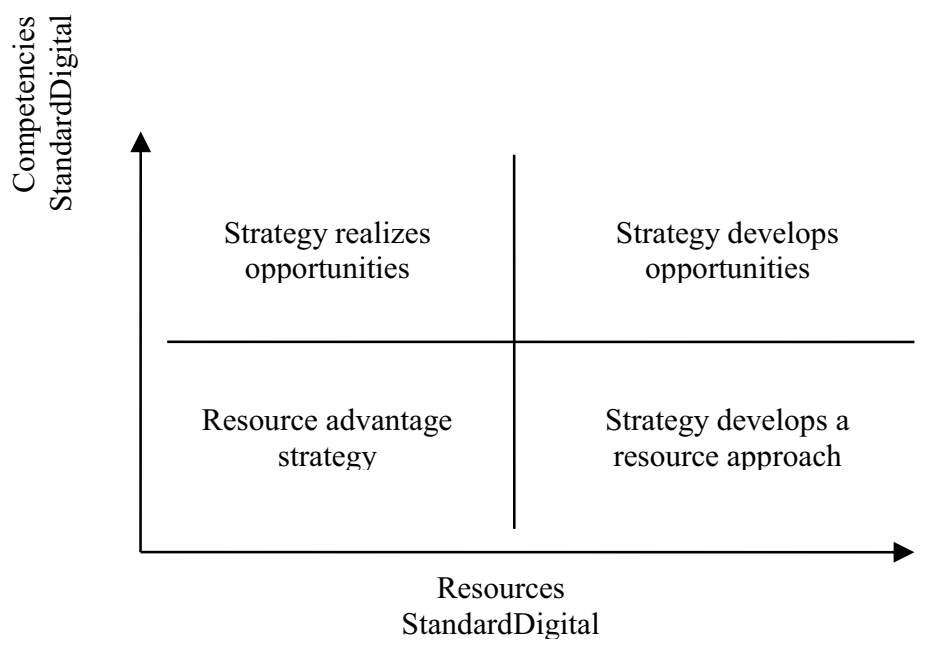

Fig. 2. Models of agricultural enterprise development in the context of digitalization.

It should be mentioned that it is the strategy implementation of developing opportunities that allows us to speak about the formation of a fundamentally new model of an agricultural enterprise activity, assuming realization of the digital development potential laid down by the "Agriculture 4.0" concept and enterprise development in the direction of the "Agriculture 5.0" formation, which implies the agricultural production activities within digital integrated enterprises that organize production processes based on the use of robotics and artificial intelligence systems.

\section{References}

1. W. Bauer, M. Hämmerle, S. Schlund, Ch. Vocke, Procedia Manufacturing 3, 417-424 (2015) doi: 10.1016/j.promfg.2015.07.200

2. A. Rojko, Int. Journal of Interactive Mobile Technologies 5, 77-90 (2017) doi: 10.3991/ijim.v11i5.7072

3. A.-T. Braun, E. Colangelo, T. Steckel, Procedia CIRP 72, 979-984 (2018) doi: 10.1016/j.procir.2018.03.176

4. I. Zambon, M. Cecchini, G. Egidi et all., Processes 7, 36 (2019) doi: 10.3390/pr7010036

5. N. Adnan, Sh. Md Nordin, I. Rahman, A. Noor, World J. Sci. Technol. Sustain. Dev. 15, 98-115 (2018) doi:10.1108/WJSTSD-11-2016-0062

6. S. Keesstra, G. Mol, J. De Leeuw, et al., Land 7, 133 (2018) doi: 10.3390/land7040133

7. A. Galati, M. Crescimanno, L. Gristina, S. Keesstra, A. Novara, Agric. Syst. 144, 5864 (2016) doi: 10.1016/j.agsy.2016.02.004

8. A.-A. Pigforda, G. Hickeya, L. Klerkx, Agricultural Systems 164, 116-121 (2018) doi: 10.1016/j.agsy.2018.04.007

9. I. Bateman, A. Harwood, G. Mace, R. Watson, Science 341, 45-50 (2013) doi: 10.1126/science. 1234379

10. A. Ustundag, E. Cevikcan (2018) doi: 10.1007/978-3-319-57870-5_1

11. S. Sonka, Farm Policy J. 12, 1-9 (2015) 
12. M. O'Grady, G. O'Hare, Information Processing in Agriculture 3, 179-187 (2017) doi: 10.1016/j.inpa.2017.05.001

13. A. Rogachev, E. Melikhova, Studies in Computational Intelligence 826, 1193-1201 (2019) doi: 10.1007/978-3-030-13397-9_122

14. I. Yurchenko, Int. J. of Advanced and Applied Sciences 2, 72-77 (2017)

15. M. de Reuver, C. Sørensen, R. Basole, Journal of Information Technology 2, 124-135 (2017) doi: 10.1057/s41265-016-0033-3 